\title{
Enhanced expression of synoviolin in peripheral blood from obese/overweight donors
}

\author{
HIDETOSHI FUJITA ${ }^{1,2}$, SATOKO ARATANI ${ }^{1,3}$, IZURU MIZOGUCHI ${ }^{4}$, \\ NAOKO YAGISHITA ${ }^{5}$ and TOSHIHIRO NAKAJIMA ${ }^{1-3,5-9}$
}

\author{
${ }^{1}$ Department of Locomotor Science, Institute of Medical Science; ${ }^{2}$ Department of Future Medical Science; \\ ${ }^{3}$ Industry-University Cooperation (BioMimetics Sympathies Inc.); ${ }^{4}$ Department of Immunoregulation, Institute of Medical \\ Science, Tokyo Medical University, Tokyo 160-8402; ${ }^{5}$ Institute of Medical Science, St. Marianna University School of Medicine, \\ Kawasaki, Kanagawa 216-8511; ${ }^{6}$ Integrated Gene Editing Section (iGES); ${ }^{7}$ Medical Research Center, Tokyo \\ Medical University Hospital, Tokyo 160-0023; ${ }^{8}$ Department of Biomedical Engineering, Osaka Institute \\ of Technology, Osaka 535-8585; ${ }^{9}$ Bayside Misato Medical Center, Kochi, Kochi 781-0112, Japan
}

Received August 27, 2018; Accepted March 6, 2019

DOI: $10.3892 / \mathrm{etm} .2020 .9249$

\begin{abstract}
Obesity is currently a major medical and societal issue. Synoviolin (SYVN1) is an E3 ubiquitin ligase involved in endoplasmic reticulum (ER) stress. Overexpression of Syvnl has been found in genetically obese mice (ob/ob and $d b / d b)$, and treatment with a Syvnl inhibitor suppresses weight gain in some mouse models (C57BL/6J and $d b / d b$ ). However, SYVN1 expression in humans has not yet been elucidated. In the present study, 35 human volunteers were analyzed, and the expression level of $S Y V N 1$ mRNA in peripheral blood mononuclear cells (PBMCs) was detected using reverse transcription-quantitative polymerase chain reaction (RT-qPCR) analysis. Expression of SYVN1 mRNA was significantly increased in PBMCs from volunteers with a BMI $\geq 25.0$, compared with volunteers with a BMI <25.0. In addition, PCR array and RT-qPCR of ER stress-responsive genes revealed that the expression of activating transcription factor 6 (ATF6), which plays an important
\end{abstract}

Correspondence to: Professor Toshihiro Nakajima, Department of Locomotor Science, Institute of Medical Science, Tokyo Medical University, 6-1-1 Shinjuku, Shinjuku-ku, Tokyo 160-8402, Japan E-mail:marlin@tokyo-med.ac.jp

Abbreviations: SYVN1, Synoviolin; PBMCs, peripheral blood mononuclear cells; RA, rheumatoid arthritis; BMI, body mass index; WHO, World Health Organization; ER, endoplasmic reticulum; UPR, unfolded protein response; ERAD, ER-associated protein degradation; PERK, PKR-like endoplasmic reticulum kinase; eIF2, eukaryotic initiation factor; ATF6, activating transcription factor 6; IRE1, inositol requiring enzyme 1; XBP1, X-box binding protein; TNF $\alpha$, tumor necrosis factor $\alpha$; IL-1, interleukin-1; GABP, GA-binding protein; ILF-3, interleukin enhancer binding protein 3; $\mathrm{PGC}$, peroxisome proliferator-activated receptor coactivator

Key words: synoviolin, ATF6, obesity, ER stress, PBMCs, biomarker role in the transcriptional activation of $S Y V N 1$, was increased in PBMCs from volunteers with a BMI $\geq 25.0$. These results suggest that the ATF6-SYVN1 axis might be an important pathway in the progression of obesity.

\section{Introduction}

Obesity is associated with excessive accumulation of adipose tissue, increased risk of diabetes, hypertension, cardiovascular diseases, and depression, and causes enormous economic and social burden (1). Although the molecular mechanisms that link obesity with a spectrum of metabolic and cardiovascular defects are not well understood, previous studies have indicated that endoplasmic reticulum (ER) stress and inflammation are stimulated in obesity $(2,3)$. There are two major responses to ER stress: the unfolded protein response (UPR) and the ER-associated protein degradation (ERAD) pathway (4). PKR-like endoplasmic reticulum kinase (PERK)-eukaryotic initiation factor (eIF2), activating transcription factor 6 (ATF6), and inositol requiring enzyme 1 (IRE1)-X-box binding protein (XBP1) are the three main signaling factors involved in the activation of the UPR pathway, and mutation or knockout of these genes results in insulin resistance in mouse models $(5,6)$. In the ERAD pathway, synoviolin (SYVN1), a mammalian homolog of yeast Hrd1p/Der3p, plays an important role as an E3 ubiquitin ligase to promote the degradation of misfolded proteins (7-9).

SYVN1 was identified from the cDNA of rheumatoid synovial cells and is overexpressed in synovial tissue and PBMCs from rheumatoid arthritis patients $(7,10)$. We demonstrated that the expression of $S Y V N 1$ is transcriptionally regulated by pro-inflammatory cytokines such as tumor necrosis factor $\alpha$ (TNF $\alpha$ ), interleukin (IL)-1, and IL-6 $(11,12)$ via Ets transcription factors, GA-binding protein (GABP) $\alpha$, GABP $\beta$ (13) and interleukin enhancer binding protein 3 (ILF-3) (14), and ER stress via ATF6 and XBP1 (15). Recently, we found that SYVN1 deficiency resulted in weight loss and a reduced accumulation of white adipose tissue in WT mice and genetically obese mice 
$(o b / o b$ and $d b / d b)(16)$. SYVN1 negatively regulated peroxisome proliferator-activated receptor coactivator (PGC)-1 $\beta$, a thermogenic coactivator via its ubiquitination. In adipose tissue, there were significantly more mitochondria, a higher mitochondrial respiration level, and an increased basal energy expenditure. Furthermore, the selective SYVN1 inhibitor LS-102 prevented obesity and accumulation of fat in mice (16). Thus, SYVN1 is a potential therapeutic target in obesity treatment. Although high expression of Syvnl has been found in the white adipose tissue of genetically obese mice (ob/ob and $d b / d b)$, the expression of SYVN1 in humans has not been elucidated.

We hypothesize that individuals with obesity/overweight will demonstrate increased expression of SYVNI compared to healthy controls. In this study, we examine the differences in the expression levels of ER stress- and inflammation-associated genes in the circulating leukocytes of Japanese volunteers with a BMI $<25.0$ compared to those with a BMI $\geq 25.0$.

\section{Materials and methods}

Volunteers. The present study was approved by ethics committee of Tokyo Medical University (no. 2728, 2729) and written informed consent was obtained from all subjects. The patient was recruited from March to June in 2015 at a hospital in Kochi prefecture in Japan. A total of 35 volunteers of Japanese origin participated in this study. Twenty four subject (68.5\%) were women and $11(31.4 \%)$ were men (mean age 39.0 years). We excluded patients who had a history of rheumatoid arthritis (RA) $(n=3)$.

Cell separation. Blood samples of $10 \mathrm{ml}$ were obtained and PBMCs were isolated by Ficoll gradient (GE Healthcare Bio-Sciences AB, Uppsala, Sweden) (17). Briefly, blood samples were centrifuged for $10 \mathrm{~min}$ at $2800 \mathrm{rpm}$, and blood cell pellets were resuspended with PBS- $10 \mathrm{ml}$ of Percoll-paque $(\mathrm{d}=1.077 \mathrm{~g} / \mathrm{ml})$ was slowly added, and then tube was centrifuged for $30 \mathrm{~min}$ at $1600 \mathrm{rpm}$. PBMCs were collected and washed with RPMI 1640 medium containing 1\% FBS.

$R N A$ isolation and reverse transcription-quantitative polymerase chain reaction (RT-qPCR) analysis. Total RNA from PBMCs was purified using ISOGEN (Nippon Gene, Tokyo, Japan) according to the manufacturer's instructions, and reverse transcribed using ReverTra Ace with random primers (Toyobo, Osaka, Japan). RT-qPCR was performed using a LightCycler 480 Probes Master (Roche Diagnostics, Mannheim, Germany). Expression levels were determined relative to that of ribosomal protein large $\mathrm{P} 0(R P L P O)$ and the mean of the control group (BMI <25.0) set to 1 . Primers and probes used in this study are shown in Table I.

PCR arrays. Five hundred nanograms of total RNA was reverse transcribed using ReverTra Ace with random primers (Toyobo, Osaka, Japan) and subsequently loaded onto either an Inflammatory Cytokines and Receptors (for measurement of inflammatory cytokine genes) or an Unfolded Protein Response (for measurement of RT stress genes) $\mathrm{RT}^{2}$ Profiler PCR Array, according to the manufacturer's instructions (Qiagen). Fold change was calculated by determining the ratio of mRNA levels to control values using the $\Delta$ threshold cycle
Table I. Primer sequences and probes.

\begin{tabular}{|c|c|c|c|}
\hline Gene & Direction $^{\mathrm{a}}$ & Primer sequence & Probe \\
\hline \multirow[t]{2}{*}{$S Y V N 1$} & $\mathrm{~F}$ & ccagtacctcaccgtgctg & $\# 16$ \\
\hline & $\mathrm{R}$ & tctgagctagggatgctggt & \\
\hline \multirow[t]{2}{*}{$R P L P O$} & $\mathrm{~F}$ & gcagaaggggagacacattt & \#62 \\
\hline & $\mathrm{R}$ & tgtggtcttgttatgggtggt & \\
\hline \multirow[t]{2}{*}{ ILI } & $\mathrm{F}$ & ggttgagtttaagccaatcca & \#6 \\
\hline & $\mathrm{R}$ & tgctgacctaggcttgatga & \\
\hline \multirow[t]{2}{*}{$T N F$} & $\mathrm{~F}$ & cagcctcttctccttcctgat & $\# 29$ \\
\hline & $\mathrm{R}$ & gccagagggctgattagaga & \\
\hline \multirow[t]{2}{*}{ IL6 } & $\mathrm{F}$ & caggagcccagctatgaact & $\# 7$ \\
\hline & $\mathrm{R}$ & gaaggcagcaggcaacac & \\
\hline \multirow[t]{2}{*}{ ATF6 } & $\mathrm{F}$ & gcagaaggggagacacattt & \#62 \\
\hline & $\mathrm{R}$ & tgtggtcttgttatgggtggt & \\
\hline \multirow[t]{2}{*}{$X B P 1$} & $\mathrm{~F}$ & ggagttaagacagcgcttgg & \#37 \\
\hline & $\mathrm{R}$ & cactggectcacttcattcc & \\
\hline \multirow[t]{2}{*}{ eIF2 } & $\mathrm{F}$ & gaagctaagaaagctgcaaagc & \#43 \\
\hline & $\mathrm{R}$ & cagtgtttcgtggtgtgctc & \\
\hline \multirow[t]{2}{*}{ IRE-1 } & $\mathrm{F}$ & gaagcatgtgctcaaacacc & $\# 50$ \\
\hline & $\mathrm{R}$ & tctgtcgctcacgtcctg & \\
\hline
\end{tabular}

${ }^{a}$ Direction of primer sequences. ${ }^{b}$ Probe numbers of Universal ProbeLibrary probes (Roche Diagnostics). F, forward; R, reverse; SYVN1, Synoviolin; RPLPO, ribosomal protein lateral stalk subunit P0; IL, interleukin; TNF, tumor necrosis factor; ATF6, activating transcription factor 6; IRE1, inositol requiring enzyme 1; XBP1, $\mathrm{X}$-box binding protein; eIF2, eukaryotic initiation factor.

(Ct) method $\left(2^{-\triangle \Delta \mathrm{Ct}}\right)$. All data were normalized to RPL13a or RPLPO mRNA. PCR conditions were: $10 \mathrm{~min}$ at $95^{\circ} \mathrm{C}$, followed by 45 cycles of $15 \mathrm{sec}$ at $95^{\circ} \mathrm{C}$ and $1 \mathrm{~min}$ at $60^{\circ} \mathrm{C}$.

Statistical analysis. All the values reported are expressed as mean \pm SE and were analyzed using Excel Statistics 2012 (SSRI Japan Co., Ltd., Tokyo). Differences between volunteers with a BMI $\geq 25.0$ and volunteers with a BMI $<25.0$ were calculated using an unpaired Student's t-test. The Mann-Whitney U test was used in the differences of ratio of women in donors. For all statistical tests, $\mathrm{P}<0.05$ was considered to indicate a statistically significant difference.

\section{Results}

Characteristics of donors. The main characteristics of the 35 volunteers are shown in detail in Table II. Of a total of 35 volunteers, $24(68.5 \%)$ were women and $11(31.4 \%)$ were men. The mean age of volunteers was 39.0 years. Our study found $25.7 \%$ (9 donors) had a BMI $\geq 25.0$ and $74.3 \%$ (26 donors) had a normal BMI of $<25.0$. Of the 9 donors with a BMI $\geq 25.0$, two thirds $(n=6)$ were classed as over weight $(25.0 \leq \leq \mathrm{BMI}<30.0)$ and the other third $(\mathrm{n}=3)$ were classed as obese (BMI $\geq \geqq 30.0$ ).

Expression of SYVN1. To investigate the level of SYVN1 mRNA in PBMCs from volunteers with a BMI $\geq 25.0$ compared with 
Table II. Characteristics of donors

\begin{tabular}{lcccc}
\hline Variable & All donors & Donor $\left(\mathrm{BMI}<25 \mathrm{~kg} / \mathrm{m}^{2}\right)(\mathrm{n}=26)$ & Donor $\left(\mathrm{BMI} \geq 25 \mathrm{~kg} / \mathrm{m}^{2}\right)(\mathrm{n}=9)$ & $42.1 \pm 3.4$ \\
\hline Age & $39.0 \pm 2.0$ & $38.0 \pm 2.4$ & $7(78)$ & 0.37 \\
Women $(\%)$ & $24(68.5)$ & $17(65)$ & $75.0 \pm 4.0$ & 0.50 \\
Weight $(\mathrm{kg})$ & $59.4 \pm 2.1$ & $53.9 \pm 1.4$ & $1.6 \pm 0.02$ & $2.7 \times 10^{-07}$ \\
Height (m) & $1.6 \pm 0.01$ & $1.6 \pm 0.02$ & $30.2 \pm 1.8$ & 0.29 \\
BMI & $23.3 \pm 0.9$ & $20.9 \pm 0.4$ & $1.6 \times 10^{-08}$
\end{tabular}

BMI, body mass index.

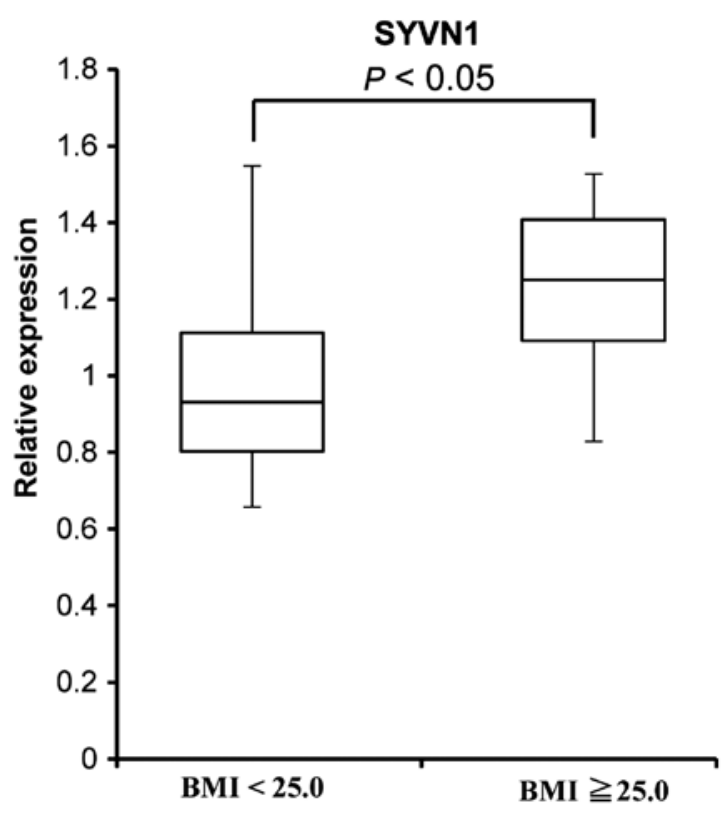

Figure 1. Expression of $S Y V N 1$ mRNA in whole peripheral blood from donors with $\mathrm{BMI} \geq 25$.0. Individual measurements were standardized using ribosomal protein lateral stalk subunit $\mathrm{P} 0$, and the mean of the control group (BMI <25.0) set to 1. Data are presented as box and whisker plots. The box denotes the first quartile and the third quartile. The line within the box is the median. The whiskers are the two lines outside the box that extend to the highest and lowest data scores. Statistical analysis by Student's t-test. Data are mean \pm standard error of the mean. SYVN1, Synoviolin 1 .

the expression in PBMCs from volunteers with a BMI $<25.0$, we performed a RT-qPCR assay (Fig. 1). SYVN1 mRNA expression was 1.2-fold higher in PBMCs from volunteers with a $\mathrm{BMI} \geq 25.0$ than in PBMCs from volunteers with a BMI $<25.0(\mathrm{P}=0.023, \mathrm{n}=35)$.

Expression of inflammatory cytokine genes. Ours and other previous studies indicate that the expression of $S Y V N 1$ is mainly regulated by inflammatory cytokine signals and ER stress signals $(11,12,15)$. Therefore, we investigated the upstream signals of SYVN1 expression. To examine the expression of inflammatory cytokines and their receptors, we performed a PCR array using an Inflammatory Cytokines and Receptors RT ${ }^{2}$ Profiler PCR Array System. We compared the expression of 84 inflammatory chemokines, cytokines, and their receptor genes. As shown in Fig. 2, the expression of $T N F \alpha$ and $I L-1$ was lower in PBMCs from volunteers with a $\mathrm{BMI} \geq 25.0$ than in those with a BMI $<25.0$. To confirm the

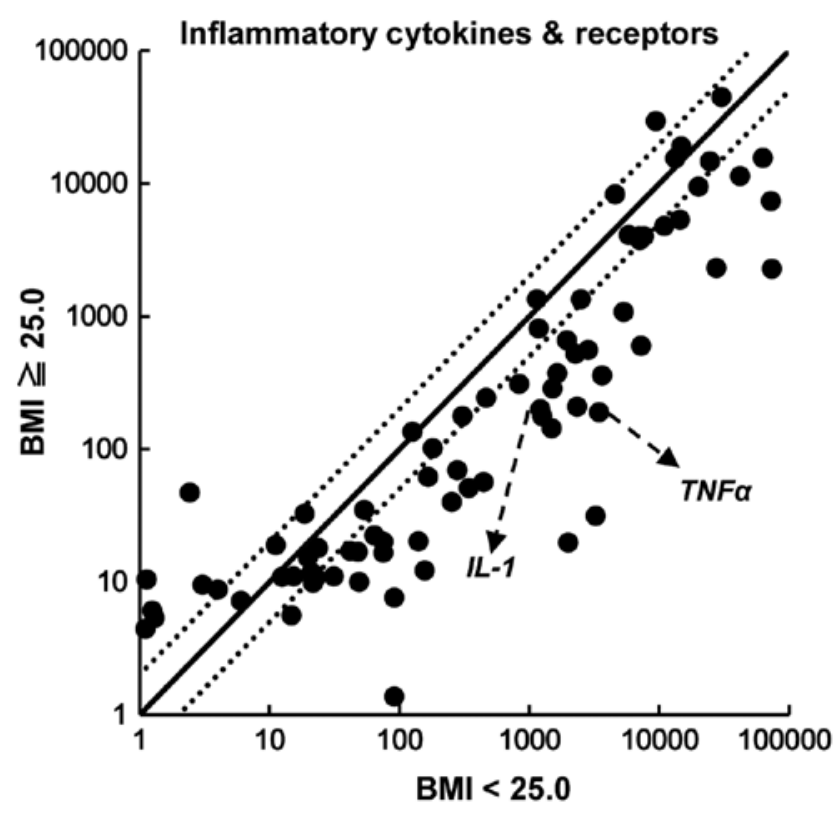

Figure 2. Inflammatory gene expression profile of whole peripheral blood from donors with $\mathrm{BMI} \geq 25.0$ and $\mathrm{BMI}<25.0$. Total mRNA transcript levels of 84 inflammatory genes were measured. Polymerase chain reaction array of whole peripheral blood from donors with $\mathrm{BMI} \geq 25.0$ and with $\mathrm{BMI}<25.0$. Dashed lines represent 2-fold change. BMI, body mass index.

results of the PCR array, we performed an RT-qPCR assay. In addition, we examined the expression of IL-6, because IL-6 regulates the expression of SYVN1 (12). As shown in Fig. 3, the expression of $T N F \alpha, I L-1$, and $I L-6$ did not significantly differ between the two groups.

Expression of ER stress genes. We next examined the expression of ER stress signals using an Unfolded Protein Response $\mathrm{RT}^{2}$ Profiler PCR Array system. The expression of ER stress-responsive genes, such as ATF6, XBP1, and $e I F 2 a$, were higher in PBMCs from volunteers with a $\mathrm{BMI} \geq 25.0$ compared with the expression in PBMCs from volunteers with a BMI $<25.0$ (Fig. 4). To confirm the results of the PCR array, we performed a RT-qPCR assay to investigate the expression of $A T F 6, X B P 1, I R E 1$, and $e I F 2 a$. We investigated the expression of IRE1, because IRE1 is important factor to regulate activity of XBP1 (18). We found that ATF6 mRNA expression was significantly higher in PBMCs from volunteers with a BMI $\geqq 25.0$ than $\mathrm{BMI}<25.0(\mathrm{P}=0.046)$ (Fig. 5). There were no statistically significant differences in the expression of $X B P 1$, 

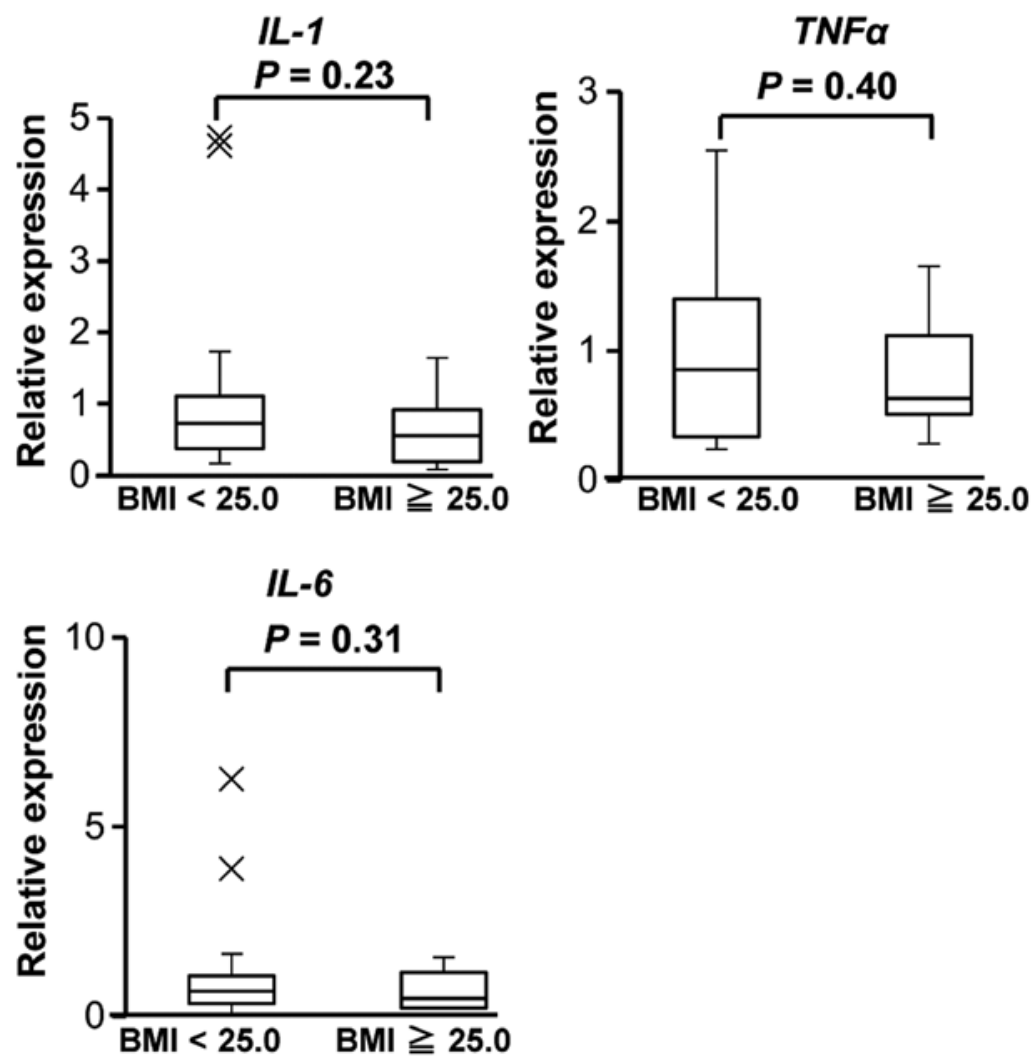

Figure 3. Expression of $I L-1, T N F-\alpha$ and $I L-6$ in whole peripheral blood from donors with BMI $\geq 25.0$. Individual measurements were standardized using ribosomal protein lateral stalk subunit P0, and the mean of the control group (BMI <25.0) set to 1. Data are presented as box and whisker plots. The box denotes the first quartile and the third quartile. The line within the box is the median. The whiskers are the two lines outside the box that extend to the highest and lowest data scores. Statistical analysis by Student's t-test. Data are mean \pm standard error of the mean. Cross (X) marks indicate outliers. BMI, body mass index; IL, interleukin; TNF, tumor necrosis factor.

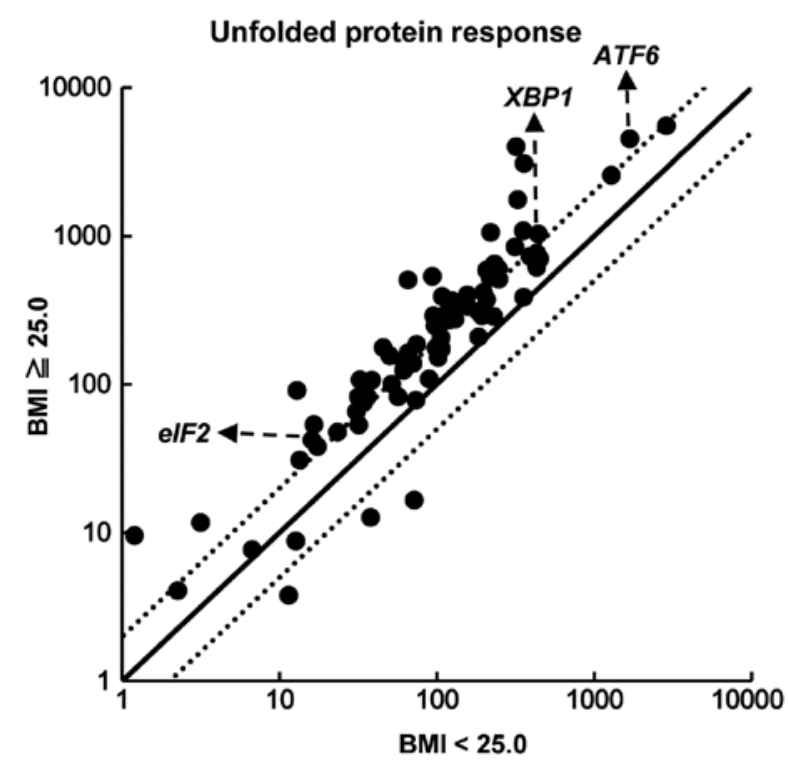

Figure 4. Expression profile of endoplasmic reticulum stress-associated genes in whole peripheral blood from donors with BMI $\geq 25.0$ and BMI $<25.0$. Total mRNA transcript levels of 84 unfolded protein response genes were measured. Polymerase chain reaction array of whole peripheral blood from donors with $\mathrm{BMI} \geq 25.0$ and with $\mathrm{BMI}<25.0$. Dashed lines represent 2 -fold change. BMI, body mass index.

$I R E 1$, and $e I F 2 a$ between volunteers with a $\mathrm{BMI} \geq 25.0$ and those with a BMI <25.0.

\section{Discussion}

In the present study, we investigated the expression of SYVNI in PBMCs from obese/overweight Japanese volunteers. We found that the level of SYVNI expression was higher in PBMCs from volunteers with a BMI $\geq 25.0$ than those with a $\mathrm{BMI}<25$.0. Previous studies, including our own, have revealed that $S Y V N 1$ is transcriptionally regulated by inflammatory cytokines including $T N F \alpha, I L-1$, and $I L-6$, and by ER stress. In the current study, the expression of $T N F \alpha, I L-1$, and $I L-6$ was not significantly different between PBMCs from donors with a BMI $\geq 25.0$ and those with a BMI $<25.0$ (Fig. 3). In addition, there were no statistically significant differences in the expression of the ER stress-responsive genes $X B P I, I R E 1$, and eIF2a (Fig. 5). However, ATF6 mRNA expression was significantly higher in PBMCs from volunteers with a BMI $\geq 25.0$ than those with a BMI $<25.0$ (Fig. 5). Taken together, these results suggest that the ATF6-SYVN1 axis may be activated in obese/overweight donors.

Previous studies have suggested that increased ER stress is associated with metabolic syndrome and type 2 diabetes. Increased levels of ER stress markers have been found in liver and adipose tissue from genetically obese mice (ob/ob, db/db) and high fat diet-induced obese mice models $(19,20)$. The expression of ER stress markers is also increased in adipose tissue and endothelial cells from obese humans $(21,22)$ and in PBMCs from patients with metabolic syndrome and type 2 diabetes $(23,24)$. In our study, the expression of SYVNI and 

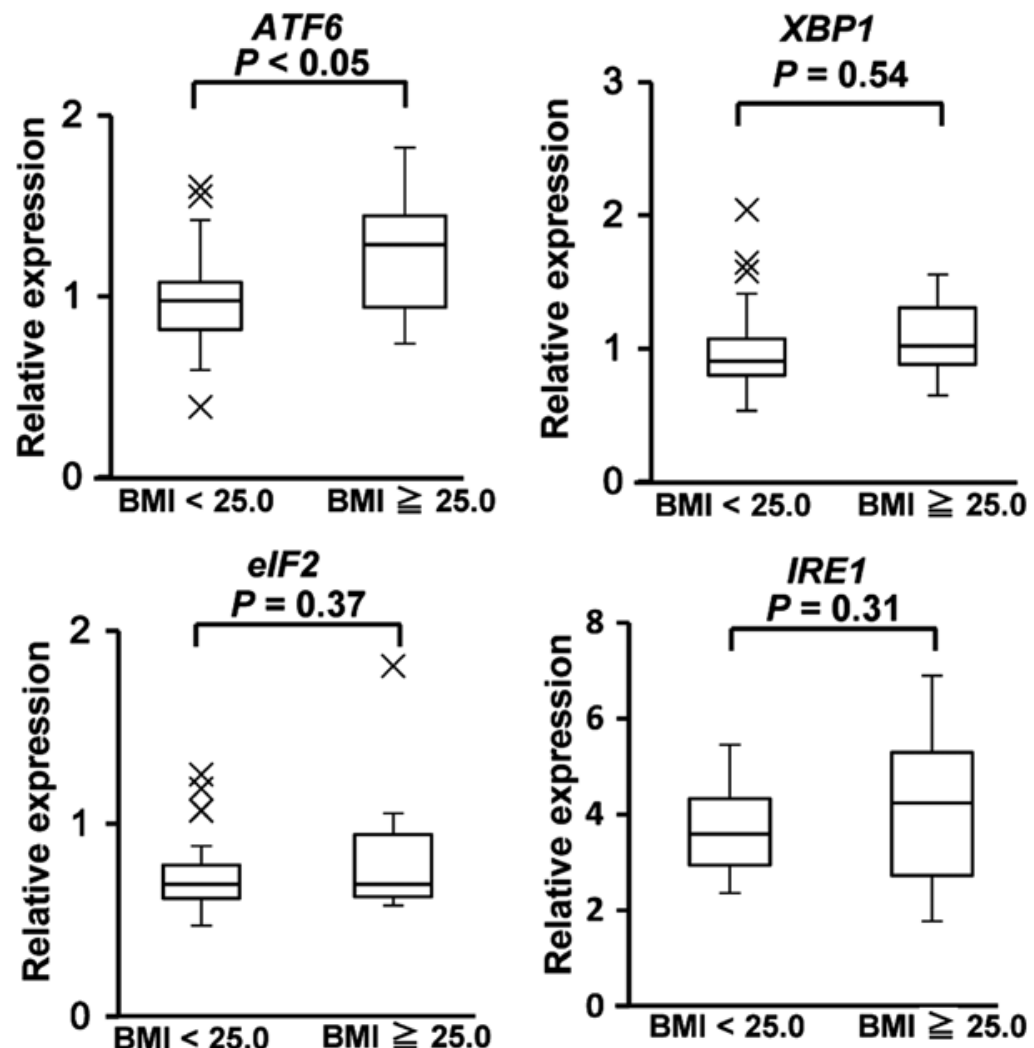

Figure 5. Expression of $A T F 6, X B P 1, e I F 2$ and $I R E 1$ in whole peripheral blood from donors with BMI $\geq 25.0$. Individual measurements were standardized using ribosomal protein lateral stalk subunit P0, and the mean of the control group (BMI <25.0) set to 1 . Data are presented as box and whisker plots. The box denotes the first quartile and the third quartile. The line within the box is median. The whiskers are the two lines outside the box that extend to the highest and lowest data scores. Statistical analysis by Student's t-test. Data are mean \pm standard error of the mean. Cross (X) marks indicate outliers. BMI, body mass index; ATF6, activating transcription factor 6; XBP1, X-Box Binding Protein 1; eIF2, Eukaryotic Translation Initiation Factor 2; IRE1, inositol requiring enzyme 1.

ATF6 was significantly increased in PBMCs from volunteers with a $\mathrm{BMI} \geq 25.0$ than those with a $\mathrm{BMI}<25.0$, whereas the expression of the ER stress markers XBP1,IRE1, and $I F 2 a$ were not (Fig. 5). Most studies on humans have examined patients with chronic conditions, whereas we investigated donors with a $\mathrm{BMI} \geq 25.0$, classed as obese/overweight. Therefore, the different expression patterns of ER stress markers might be dependent on whether patients have a chronic condition.

SYVN1 is associated with both RA and overweight/obesity. In recent years, it has become clear that obesity is a risk factor for the onset of RA and to biologics $(25,26)$. We previously demonstrated that $S Y V N 1$ was present in the cDNA of rheumatoid synovial cells and that overexpression of Syvnl in transgenic mice leads to advanced arthropathy via reduction of apoptosis in synoviocytes (7). Toh et al (10) demonstrated that the expression of $S Y V N 1$ is also increased in human PBMCs from RA patients compared with those from controls. In addition, the expression of $S Y V N 1$ was reduced in responders, but not nonresponders, of infliximab treatment, suggesting that the expression of SYVNI in PBMCs could be marker for nonresponders of infliximab treatment. In the present study, we found that elevated levels of SYVN1 were present in circulating PBMCs from volunteers with a BMI $\geq 25.0$. We previously demonstrated that high expression of Syvnl was observed in obese mice ( $d b / d b$ and $o b / o b$ mice), whereas conditional knockout mice of Syvnl revealed that loss of Syvnl expression induced reduced body weight. In addition, treatment with the SYVN1 inhibitor LS-102 attenuated weight gain in $\mathrm{C} 57 \mathrm{BL} / 6 \mathrm{~J}$ and $d b / d b$ mice. These studies suggested that the expression level of $S Y V N 1$ in PBMCs could be marker of overweight/obesity and that SYVN1 has a pivotal role in overweight/obesity and RA, and it is possible that SYVN1 is involved in onset of RA and chronic inflammation due to obesity, and also sensitivity to treatment.

Taken together, in the present study we provide evidence that the expression of SYVNl was higher in circulating PBMCs from volunteers with a BMI $\geq 25.0$ compared to those with a BMI of $<25.0$. The small sample number and the low proportion of obese patients are limitations of our study. Further analysis on a large scale, with more participants, will be needed to determine whether the expression of SYVNI has the potential to become a biomarker and will also help contribute to the understanding of the physiological significance of SYVN1 regulation.

\section{Acknowledgements}

The authors thank Mr. S. Shibata (Tokyo Medical University) for technical assistance. The authors also thank all members of Dr. Nakajima's laboratory and Dr. Khin Thuzar Wynn (Yangon Speciality Hospital).

\section{Funding}

The present study was supported in part by the Japan Society for the Promotion of Science KAKENHI (grant 
nos. 23659176, 26670479, 26461478 and 16H05157). This study was also supported in part by funds provided through a MEXT-Supported program of the Strategic Research Foundation at Private Universities (S1411011, 2014-2018) from the Ministry of Education, Culture, Sports, Science and Technology of Japan. This work was funded in part by grants from the Naito Foundation, Natural Science Scholarship Daiichi-Sankyo Foundation of Life Science, Mitsubishi, Tanabe Pharma Corporation, Bureau of Social Welfare and Public Health, Academic contribution of Pfizer, Eisai, Santen Pharmaceutical, Abbvie, Takeda Science Foundation, AstraZeneca (R\&D Grant 2013), and ONO Medical Research Foundation and Industry-University Cooperation (BioMimetics Sympathies Inc.).

\section{Availability of data and materials}

All data generated or analyzed during this study are included in this published article.

\section{Authors' contributions}

HF, SA, NY and TN conceived the project and designed the experiments. HF, SA, IM and TN performed experiments and analyzed data. HF and TN wrote the manuscript. All authors discussed the results and commented on the manuscript.

\section{Ethics approval and consent to participate}

All human experimental protocols in this study (no. 2728, 2729) were approved by the Ethics Review Committee of Tokyo Medical University. Written informed consent was obtained from all participants prior to collection of joint tissue samples.

\section{Patient consent for publication}

Consent for publication was obtained from all participants.

\section{Competing interests}

The authors and employees of BioMimetics Sympathies Inc. have declared that they have no competing interests.

\section{References}

1. Wickelgren I: Obesity: How big a problem? Science 280: 1364-1367, 1998.

2. Roden $\mathrm{M}$ and Bernroider E: Hepatic glucose metabolism in humans-its role in health and disease. Best Pract Res Clin Endocrinol Metab 17: 365-383, 2003.

3. Hotamisligil GS: Role of endoplasmic reticulum stress and c-Jun NH2-terminal kinase pathways in inflammation and origin of obesity and diabetes. Diabetes 54 (Suppl 2): S73-S78, 2005.

4. Tsai YC and Weissman AM: The unfolded protein response, degradation from endoplasmic reticulum and cancer. Genes Cancer 1: 764-778, 2010.

5. Cnop M, Foufelle F and Velloso LA: Endoplasmic reticulum stress, obesity and diabetes. Trends Mol Med 18: 59-68, 2012.

6. Wang S and Kaufman RJ: The impact of the unfolded protein response on human disease. J Cell Biol 197: 857-867, 2012.

7. Amano T, Yamasaki S, Yagishita N, Tsuchimochi K, Shin H, Kawahara K, Aratani S, Fujita H, Zhang L, Ikeda R, et al: Synoviolin/Hrd1, an E3 ubiquitin ligase, as a novel pathogenic factor for arthropathy. Genes Dev 17: 2436-2449, 2003.
8. Bernasconi R, Galli C, Calanca V, Nakajima T and Molinari M: Stringent requirement for HRD1, SEL1L, and OS-9/XTP3-B for disposal of ERAD-LS substrates. J Cell Biol 188: 223-235, 2010.

9. Yagishita N, Yamasaki S, Nishioka K and Nakajima T: Synoviolin, protein folding and the maintenance of joint homeostasis. Nat Clin Pract Rheumatol 4: 91-97, 2008.

10. Toh ML, Marotte H, Blond JL, Jhumka U, Eljaafari A, Mougin B and Miossec P: Overexpression of synoviolin in peripheral blood and synoviocytes from rheumatoid arthritis patients and continued elevation in nonresponders to infliximab treatment. Arthritis Rheum 54: 2109-2118, 2006.

11. Gao B, Calhoun K and Fang D: The proinflammatory cytokines IL-1beta and TNF-alpha induce the expression of Synoviolin, an E3 ubiquitin ligase, in mouse synovial fibroblasts via the Erk1/2-ETS1 pathway. Arthritis Res Ther 8: R172, 2006.

12. Xu YM, Wang HJ, Chen F, Guo WH, Wang YY, Li HY, Tang JH, Ding Y, Shen YC, Li M, et al: HRD1 suppresses the growth and metastasis of breast cancer cells by promoting IGF-1R degradation. Oncotarget 6: 42854-42867, 2015.

13. Tsuchimochi K, Yagishita N, Yamasaki S, Amano T, Kato Y, Kawahara K, Aratani S, Fujita H, Ji F, Sugiura A, Izumi T, et al: Identification of a crucial site for synoviolin expression. Mol Cell Biol 25: 7344-7356, 2005.

14. Izumi T,Fujii R,Izumi T,Nakazawa M, Yagishita N, Tsuchimochi K, Yamano Y, Sato T, Fujita H, Aratani S, et al: Activation of synoviolin promoter in rheumatoid synovial cells by a novel transcription complex of interleukin enhancer binding factor 3 and GA binding protein alpha. Arthritis Rheum 60: 63-72, 2009.

15. Kaneko M, Yasui S, Niinuma Y, Arai K, Omura T, Okuma Y and Nomura Y: A different pathway in the endoplasmic reticulum stress-induced expression of human HRD1 and SEL1 genes. FEBS Lett 581: 5355-5360, 2007.

16. Fujita H, Yagishita N, Aratani S, Saito-Fujita T, Morota S, Yamano Y, Hansson MJ, Inazu M, Kokuba H, Sudo K, et al: The E3 ligase synoviolin controls body weight and mitochondrial biogenesis through negative regulation of PGC-1 $\beta$. EMBO J 34: 1042-1055, 2015.

17. Ulmer AJ, Scholz W, Ernst M, Brandt E and Flad HD: Isolation and subfractionation of human peripheral blood mononuclear cells (PBMC) by density gradient centrifugation on Percoll. Immunobiology 166: 238-250, 1984.

18. Yoshida H, Matsui T, Yamamoto A, Okada T and Mori K: XBP1 mRNA is induced by ATF6 and spliced by IRE1 in response to ER stress to produce a highly active transcription factor. Cell 107: 881-891, 2001.

19. Nakatani Y, Kaneto H, Kawamori D, Yoshiuchi K, Hatazaki M, Matsuoka TA, Ozawa K, Ogawa S, Hori M, Yamasaki Y and Matsuhisa M: Involvement of endoplasmic reticulum stress in insulin resistance and diabetes. J Biol Chem 280: 847-851, 2005.

20. Ozcan U, Cao Q, Yilmaz E, Lee AH, Iwakoshi NN, Ozdelen E, Tuncman G, Görgün C, Glimcher LH and Hotamisligil GS: Endoplasmic reticulum stress links obesity, insulin action, and type 2 diabetes. Science 306: 457-461, 2004.

21. Kaplon RE, Chung E, Reese L, Cox-York K, Seals DR and Gentile CL: Activation of the unfolded protein response in vascular endothelial cells of nondiabetic obese adults. J Clin Endocrinol Metab 98: E1505-E1509, 2013.

22. Sharma NK, Das SK, Mondal AK, Hackney OG, Chu WS, Kern PA, Rasouli N, Spencer HJ, Yao-Borengasser A and Elbein SC: Endoplasmic reticulum stress markers are associated with obesity in nondiabetic subjects. J Clin Endocrinol Metab 93: 4532-4541, 2008.

23. Komura T, Sakai Y, Honda M, Takamura T, Matsushima K and Kaneko S: CD14+ monocytes are vulnerable and functionally impaired under endoplasmic reticulum stress in patients with type 2 diabetes. Diabetes 59: 634-643, 2010.

24. Sage AT, Holtby-Ottenhof S, Shi Y, Damjanovic S, Sharma AM and Werstuck GH: Metabolic syndrome and acute hyperglycemia are associated with endoplasmic reticulum stress in human mononuclear cells. Obesity (Silver Spring) 20: 748-755, 2012.

25. Qin B, Yang Y, Yang Z and Zhong R: Response to: 'Body mass index and the risk of rheumatoid arthritis: A systematic review and dose-response meta-analysis'-authors'reply. Arthritis Res Ther 17: 86, 2015.

26. Ljung L and Rantapää-Dahlqvist S: Abdominal obesity, gender and the risk of rheumatoid arthritis-a nested case-control study. Arthritis Res Ther 18: 277, 2016. 